University of Nebraska - Lincoln

DigitalCommons@University of Nebraska - Lincoln

Mechanical \& Materials Engineering Faculty

Publications

Mechanical \& Materials Engineering,

Department of

2017

\title{
Micro/nanostructures formation by femtosecond laser surface processing on amorphous and polycrystalline Ni60Nb40
}

\author{
Edwin Peng \\ University of Nebraska-Lincoln, epeng2@unl.edu \\ Alfred Tsubaki \\ University of Nebraska-Lincoln, s-atsubak1@unl.edu \\ Craig A. Zuhlke \\ University of Nebraska-Lincoln, czuhlke@unl.edu \\ Meiyu Wang \\ University of Nebraska-Lincoln \\ Ryan Bell \\ University of Nebraska-Lincoln
}

See next page for additional authors

Follow this and additional works at: https://digitalcommons.unl.edu/mechengfacpub

Part of the Mechanics of Materials Commons, Nanoscience and Nanotechnology Commons, Other

Engineering Science and Materials Commons, and the Other Mechanical Engineering Commons

Peng, Edwin; Tsubaki, Alfred; Zuhlke, Craig A.; Wang, Meiyu; Bell, Ryan; Lucis, Michael J.; Anderson, Troy P.; Alexander, Dennis R.; Gogos, George; and Shield, Jeffrey E., "Micro/nanostructures formation by femtosecond laser surface processing on amorphous and polycrystalline Ni60Nb40" (2017). Mechanical \& Materials Engineering Faculty Publications. 324.

https://digitalcommons.unl.edu/mechengfacpub/324

This Article is brought to you for free and open access by the Mechanical \& Materials Engineering, Department of at DigitalCommons@University of Nebraska - Lincoln. It has been accepted for inclusion in Mechanical \& Materials Engineering Faculty Publications by an authorized administrator of DigitalCommons@University of Nebraska Lincoln. 


\section{Authors}

Edwin Peng, Alfred Tsubaki, Craig A. Zuhlke, Meiyu Wang, Ryan Bell, Michael J. Lucis, Troy P. Anderson, Dennis R. Alexander, George Gogos, and Jeffrey E. Shield 
Published in final edited form as:

Appl Surf Sci. 2017 February 28; 396: 1170-1176. doi:10.1016/j.apsusc.2016.11.107.

Copyright (c) 2016 Elsevier B.V.

\title{
Micro/nanostructures formation by femtosecond laser surface processing on amorphous and polycrystalline $\mathrm{Ni}_{60} \mathrm{Nb}_{40}$
}

\author{
Edwin Peng ${ }^{\mathrm{a},{ }^{*},}$, Alfred Tsubaki ${ }^{\mathrm{b}}$, Craig A. Zuhlke $^{\mathrm{b}}$, Meiyu Wang ${ }^{\mathrm{a}}$, Ryan Bell ${ }^{\mathrm{b}}$, Michael J. \\ Lucis $^{a}$, Troy P. Anderson ${ }^{b}$, Dennis R. Alexander ${ }^{b}$, George Gogos ${ }^{a}$, and Jeffrey E. Shield ${ }^{a}$ \\ aDepartment of Mechanical and Materials Engineering, University of Nebraska-Lincoln, Lincoln, \\ NE 68588, USA \\ bDepartment of Electrical and Computer Engineering, University of Nebraska-Lincoln, Lincoln, NE \\ 68588, USA
}

\section{Abstract}

Femtosecond laser surface processing is a technology that can be used to functionalize many surfaces, imparting specialized properties such as increased broadband optical absorption or superhydrophilicity/superhydrophobicity. In this study, two unique classes of surface structures, below surface growth (BSG) and above surface growth (ASG) mounds, were formed by femtosecond laser surface processing on amorphous and polycrystalline $\mathrm{Ni}_{60} \mathrm{Nb}_{40}$ with two different grain sizes. Cross sectional imaging of these mounds revealed thermal evidence of the unique formation processes for each class of surface structure. BSG mounds formed on all three substrates using the same laser parameters had similar surface morphology. The microstructures in the mounds were unaltered compared with the substrate before laser processing, suggesting their formation was dominated by preferential valley ablation. ASG mounds had similar morphology when formed on the polycrystalline $\mathrm{Ni}_{60} \mathrm{Nb}_{40}$ substrates with $100 \mathrm{~nm}$ and 2 [H9262]m grain size. However, the ASG mounds had significantly wider diameter and higher peak-to-valley heights when the substrate was amorphous $\mathrm{Ni}_{60} \mathrm{Nb}_{40}$. Hydrodynamic melting was primarily responsible for ASG mound formation. On amorphous $\mathrm{Ni}_{60} \mathrm{Nb}_{40}$ substrates, the ASG mounds are most likely larger due to lower thermal diffusivity. There was clear difference in growth mechanism of femtosecond laser processed BSG and ASG mounds, and grain size does not appear to be a factor.

\section{Keywords}

Femtosecond laser; Ni60Nb40; Microstructure; Laser ablation

\section{Introduction}

\begin{abstract}
Processing with ultrafast lasers is an emerging technique for the creation of functionalized surfaces through the formation of self-organized, multiscale structures [1-4]. This type of laser processing is applicable for a wide range of materials, including metals [5-9], semiconductors [10,11], polymers [12-14], glass [15,16] and ceramics $[17,18]$.
\end{abstract}

\footnotetext{
*Corresponding author. edwin.peng@ @uskers.unl.edu (E. Peng).
} 
The resulting micro/nanostructures provide tailored surface properties with many promising applications in diverse fields. One important application is the "hyperdoping" of silicon, where ultrafast laser processing resulted in increased dopant concentration and multiscale surface structures $[19,20]$. Hyperdoped silicon can be used for increased light absorption of photo-voltaics $[17,21,22]$ and optical sensors [23,24]. Laser processed surfaces can also exhibit special wetting/wicking properties, such as superhydrophobicity or superhydrophilicity[25-27]. Potentials uses include enhanced heat transfer [28-30], selfcleaning surfaces[31], biomedical implants [32,33], drag reduction [34], and chemical sensors [35].

Surface micro/nanostructures formed by femtosecond laser processing on metals feature great diversity in morphology and size[8]. Low laser fluence near the ablation threshold of the target material, forms laser-induced periodic surface structures (LIPSS) and nanoparticle-covered pyramids [6,36-38]. LIPSS are ripples oriented either parallel or perpendicular to the laser polarization, depending on the target material and laser parameters, and have periods with the same order of magnitude as the laser wavelength [8,38,39]. They form after a low number of laser pulses ( 10-1000) [2]. After additional laser pulses (2000+) in the same fluence range of LIPSS, NCPs can develop [36-38]. These structures can be as tall as 50 [H9262]m in height, and are covered with a layer of nanoparticles typically more than 2 [H9262]m thick. These start as small ( $<10$ [H9262]m) precursor cones that increase in height, relative to the surrounding valley via preferential laser ablation. These pyramids increase in size by redeposition of nanoparticles produced during the laser ablation process $[36,40]$.

Femtosecond laser surface processing on a metal surface at a laser fluence an order of magnitude higher or more than the ablation threshold can lead to formation of mound-like structures [5,41]. These mounds can reach tens of microns in width and height, and are covered by additional, smaller scale micro/nanostructuring. These mound-like structures are of great research interest because they can be used to produce functionalized metal surfaces that are either superhydrophobic [42] or superhydrophilic [29]. For example, it was demonstrated that such superhydrophilic surfaces can enhance two-phase heat transfer $[28,30]$. Mounds can be further divided into two distinct classes: below-surface-growth (BSG) and above-surface-growth (ASG) mounds [5,40,43]. BSG mounds are tightly spaced, have low height-to-width aspect ratio ( 1:1), and have peaks which are below the original target surface. In contrast, ASG mounds are spaced farther apart, separated by pits, have high aspect ratio (>2:1), and protrude up to several [H9262] m above the original surface. In previous studies by Zuhlke et al. of femtosecond laser surface processing on Ni-based alloys 200/201 showed that BSG mound formation occurred in the fluence range of approximately $1-2 \mathrm{~J} \mathrm{~cm}^{-2}$ and ASG mounds at approximately $2-3 \mathrm{~J} \mathrm{~cm}^{-2}[5,40,43]$, as much as two orders of magnitude higher laser fluence than the ablation threshold of $\mathrm{Ni}\left(0.05-0.1 \mathrm{~J} \mathrm{~cm}^{-2}\right)$ $[44,45]$.

\section{Theory}

BSG and ASG mounds are thought to originate by small precursor ripples, mounds and pits that develop after a low number of laser pulses. For Ni 200/201, this occurs at about $<120$ 
pulses for BSG and <30 pulses for ASG mounds [5]. These precursor sites cause a nonuniform distribution of laser energy, leading to the formation processes thought to produce BSG and ASG mounds [5,40].

One of the formation processes associated with mounds is preferential valley ablation. This is the process where the valleys, or low areas of the surface, are ablated more than the peak or top of precursor mounds $[5,38,46]$. As illustrated in Fig. 1, two phenomena contribute to preferential valley ablation: (a) the higher fluence in the valleys (labelled as "1" on Fig. 1) than on the sides of the mounds due to larger subtended area resulting from increased incident angle (labelled as " 2 " on Fig. 1), and (b) a portion of the light incident on the sides of the peaks is scattered onto the valleys. BSG mounds on metals are believed to be formed primarily through preferential valley ablation, similar to "spikes" that formed on $\mathrm{Si}$ substrates[47].

A second mound formation mechanism is hydrodynamical fluid flow. This is the process where, during ultrafast laser pulse irradiation, the substrate surface melts and the resulting liquid layer flows away from the valleys up the sides of the structures and onto the peaks [48-50]. Resolidification of this layer increases the height of the peaks, and is thought to be a significant part of the ASG mound formation process $[5,46]$. Fluid flow could be the result of higher laser fluence at valleys versus sides, or could be due to laser-induced shock waves [51,52].

Lastly, redeposition of ablated material can also contribute to mound growth, most likely in the form of smaller, micrometer-sized hemispherical caps that decorate the top of ASG mounds. Redeposition can be described as vapor-liquid-solid growth, where a plume of vaporized metal is solidified and deposited on top of the mounds in the form of nanoparticles $[5,38,40]$.

Currently, there has not been a comprehensive model of femtosecond laser surface processed micro/nanostructures formation due to the complexity of the process. Such a model would have to account for many potential formation mechanisms and multiple types of surface structures. There are several theories developed to explain LIPSS formation on Si substrates [53,54], along with several predictive computer models [49,55]. However, there has not been a fully comprehensive understanding of the formation of larger femtosecond laser processed structures, e.g. NCPs, BSG and ASG mounds, on metals. Knowledge of such growth mechanisms will aid in understanding the physics behind laser-matter interaction, and can improve the performance of functionalized surfaces in applications such as heat transfer and self-cleaning.

\section{Materials and methods}

It has been proposed that the precursor sites for these femtosecond laser surface processed micro/nanostructures originate at micro/nanoscale defects present in the original metal surface [5,40,56]. Possible initiation sites for mound growth are grain boundaries [56]. The typical grain size for the $\mathrm{Ni}$, stainless steel, and Ti surfaces in previous femtosecond laser processing studies are on the order of one to tens of microns, the same length scale as these 
mounds [7]. There has been some previous work on grain boundary effects on LIPSS formation [56], but none to our knowledge on these larger-scale surface structures. In this study, the ablation threshold and femtosecond laser surface processing mound formation are compared on three substrates with identical chemical composition, but different crystalline microstructure: two different grain sizes, and one amorphous (i.e. without any grain boundaries).

The alloy utilized in this study was the well-characterized, easy glass-forming $\mathrm{Ni}_{60} \mathrm{Nb}_{40}$ [57,58]. Arc-melting and melt spinning formed amorphous $\mathrm{Ni}_{60} \mathrm{Nb}_{40}$ ribbons as described in previous published study[46]. Ribbons were sealed in quartz tube under Ar atmosphere after repeated evacuation cycles to prevent oxidation. Then, they were annealed in a tube furnace at $1373 \mathrm{~K}$ for either 2 or $20 \mathrm{~h}$ to obtain polycrystalline structures with two different grain sizes.

Subsequent polycrystalline $\mathrm{Ni}_{60} \mathrm{Nb}_{40}$ microstructures were characterized using SEM and energy dispersive $\mathrm{x}$-ray spectroscopy (EDS) in the FEI Helios NanoLab DualBeam. X-ray diffraction (XRD) using Cu K[H9251] radiation in a Bruker-AXS D8 Discover X-ray Diffractometer provided phase analysis. All XRD samples were mounted on a zerobackground holder made from an off-cut Si single crystal. Ribbon surfaces were polished through standard metallurgical procedures, with final polish using $0.05[\mathrm{H9262}] \mathrm{m} \mathrm{Al}_{2} \mathrm{O}_{3}$ powder, in preparation for femtosecond laser surface processing. The polished ribbons were cleaned in an ultrasonic bath through successively submerging in acetone, methanol, and deionized water for $20 \mathrm{~min}$ each.

Femtosecond laser surface processing was carried out using a Ti:Sapphire femtosecond laser system, Spectra Physics Spitfire as previously described[46]. The laser spot size, which was used to calculate the laser fluence and pulse count, along with ablation threshold, was determined using the method outlined by Liu [59].

All three different substrates, with the three different microstructures, were subject to identical femtosecond laser surface processing parameters to create each type of mound. The laser beam spot diameter was 206 [H9262]m. BSG mounds were produced using 515 laser pulses at a peak fluence of $2.14 \mathrm{~J} \mathrm{~cm}^{-2}$, with translation speed and pitch of $3 \mathrm{~mm} \mathrm{~s}^{-1}$ and 15 [H9262]m, respectively. This laser fluence was chosen as it was close to the minimum required for BSG mound formation on $\mathrm{Ni}_{60} \mathrm{Nb}_{40}$. The ASG mounds were fabricated using 175 laser pulses with a peak laser fluence of $6.10 \mathrm{~J} \mathrm{~cm}^{-2}$, with translation speed and pitch of $4.5 \mathrm{~mm} \mathrm{~s}^{-1}$ and 15 [H9262] $\mathrm{m}$, respectively. The chosen laser fluence was at the high end for ASG mound formation to ensure surface structures that were distinct from BSG mounds. These fluence values for femtosecond laser surface processing mound formation on $\mathrm{Ni}_{60} \mathrm{Nb}_{40}$ were found to be about twice that for $\mathrm{Ni} 200 / 201$ [5]. However, the previous $\mathrm{Ni}$ 200/201 mound-formation work was performed with a square top-hat beam profile, while this study utilized a Gaussian beam profile. Due to larger variations in fluence across the Gaussian profile, a higher peak laser fluence is generally required to achieve the same surface structures. The laser pulse counts were chosen for maximum growth of both types of mounds. Evolution of surface structures as a function of laser pulse counts was similar to what was previously used for femtosecond laser processing of Ni 200/201, on which the 
final, saturated BSG and ASG structures were reached after 600 and 150 pulses, respectively [5].

The underlying microstructure of these BSG and ASG mounds, as revealed by examination of cross-sections, can provide information on their formation mechanisms, such as evidence of thermal events like fluid flow or defects that serve as ablation precursor sites. There have been several previous studies on femtosecond laser surface processing of silicon and metals that utilize cross sections for this purpose [7,40,46,60,61]. SEM imaging and cross sectional milling of the BSG and ASG mounds were performed with the FEI Helios NanoLab 660 DualBeam. This technique is a modification of the TEM "liftout" sample preparation process [62,63]. The target mound was first protected by Pt layers deposited via electronbeam induced deposition (100 nm thick) and ion beam-induced deposition (2 [H9262]m thick). Then, focused ion beam (FIB) milling using $\mathrm{Ga}^{+}$removed approximately half of the mound and the surrounding material to reveal the resulting cross-section. Imaging was per formed using ion-induced secondary electrons (ISE) at a tilt of $52^{\circ}$.

\section{Results}

\section{1. $\mathrm{Ni}_{60} \mathrm{Nb}_{40}$ substrate analysis}

Fig. 2(a) shows the XRD scan of the melt-spun $\mathrm{Ni}_{60} \mathrm{Nb}_{40}$ ribbons, which revealed an amorphous structure as indicated by the diffuse x-ray diffraction maxima. The XRD patterns of the annealed $\mathrm{Ni}_{60} \mathrm{Nb}_{40}$ ribbons were revealed to be polycrystalline, with peaks indexing to two distinct phases: orthorhombic $\mathrm{Ni}_{3} \mathrm{Nb}$ and rhombohedral $\mathrm{Ni}_{6} \mathrm{Nb}_{7}$ (Fig. 2(b) \& (c)). These two intermetallic compounds were consistent with what was expected from the equilibrium phase diagram at the $\mathrm{Ni}_{60} \mathrm{Nb}_{40}$ composition [64-66]. SEM images (Fig. 3) revealed a two phase structure for ribbons annealed for 2 and $20 \mathrm{~h}$ that was consistent with XRD analysis. The average $\mathrm{Ni}_{3} \mathrm{Nb}$ grain size was approximately $100 \mathrm{~nm}$ after the $2 \mathrm{~h}$ heat treatment and 2 [H9262] $\mathrm{m}$ after the $20 \mathrm{~h}$ heat treatment. The individual $\mathrm{Ni}_{6} \mathrm{Nb}_{7}$ grains were not evident due to weak channeling contrast between differently-oriented grains. Locationspecific EDS spectra were collected by EDAX Octane Silicon Drift Detector (SDD). A semi-quantitative EDS analysis was performed with the EDAX TEAM EDS software. The analysis revealed the composition of the light-colored grains to be $75.9 \pm 0.9$ at. $\% \mathrm{Ni}$ and $24.1 \pm 0.5$ at. \% $\mathrm{Nb}$, close to the expected $\mathrm{Ni}_{3} \mathrm{Nb}$ phase composition. The composition of the darker regions was determined to be $45.7 \pm 1.0$ at.\% $\mathrm{Ni}$ and $54.3 \pm 1.5$ at.\% $\mathrm{Nb}$, which correspond to the $\mathrm{Ni}_{6} \mathrm{Nb}_{7}$ phase.

\subsection{Ablation threshold}

Ablation threshold testing was performed with 100 pulses of $50 \mathrm{fs}$ duration from 50 to 700 $\mu \mathrm{J}$ pulse energy with $50 \mu \mathrm{J}$ increments. The Keyence VK-X 3D Laser Scanning Confocal Microscope (3DLSCM) was used to measure ablation crater area and calculate diameter of the equivalent circular area (i.e., $20 \mu \mathrm{m}$ diameter for $314 \mu \mathrm{m}^{2}$ ablated area). Four sets of such ablation spots were analyzed on each of the three substrates. The square of the diameter was plotted against the natural log of laser power and fitted linearly to determine laser spot radius and threshold fluence[59]. 
The average ablation test results for each form of $\mathrm{Ni}_{60} \mathrm{Nb}_{40}$ are displayed in Table 1 . There was no statistical difference in the threshold fluence, nor the expected ablation spot size at threshold fluence for the three types of substrates.

\subsection{BSG \& ASG mound morphology}

Fig. 4 displays SEM images of the BSG and ASG mounds on amorphous and polycrystalline $\mathrm{Ni}_{60} \mathrm{Nb}_{40}$. ASG mounds are larger than BSG mounds and separated by deep pits. This was consistent with results of previous femtosecond laser surface processing mound formation on Ni $[5,40]$. Both BSG and ASG mounds feature ridges that were perpendicular to the polarization of the incident ablation pulses.

The 3DLSCM was used to analyze differences between mounds formed on the three substrate microstructures of $\mathrm{Ni}_{60} \mathrm{Nb}_{40}$. Four commonly used parameters for characterizing laser processed surface structure morphology were measured, including: peak-to-peak distance (PPD), surface-area-to-geometric area ratio (SA/GA), average peak-to-valley height $\left(\mathrm{R}_{\mathrm{z}}\right)$, and root-mean-square roughness $\left(\mathrm{R}_{\mathrm{RMS}}\right)[14,28,30,67]$. For each combination of substrate and mound type, ten raster samples were measured, with the standard deviation used as a measure of the uncertainty associated with each parameter.

If grain boundaries play an important role in femtosecond laser processed structure formation, one would expect differences in morphology between mounds grown on substrates with different microstructures. However, there was no statistical difference between the morphology of BSG mounds on polycrystalline $\mathrm{Ni}_{60} \mathrm{Nb}_{40}$ with $100 \mathrm{~nm}$ and 2 $\mu \mathrm{m}$ grain sizes (Table 2). Femtosecond laser surface processing of both substrate types produced mounds with similar average PPD, SA/GA of 3.9, and roughness. From the data presented in Table 3, the polycrystalline grain size also did not appear to produce differences in ASG mound morphology. While the mean of all four parameters for ASG mounds on the $2 \mu \mathrm{m}$ grain size substrate was larger than those on the $100 \mathrm{~nm}$ grain size substrates, all were within the experimental error. As both BSG and ASG mounds were grown on substrates with different initial microstructures, this suggest that polycrystalline grain size does not influence morphology for these high-fluence surface structures. For surface structures formed at lower fluence, such as LIPSS or NCPs, grain size may play a larger role as other researchers have reported [56].

Femtosecond laser surface processing on amorphous $\mathrm{Ni}_{60} \mathrm{Nb}_{40}$ produced BSG mounds with the same mean morphology parameters as on polycrystalline $\mathrm{Ni}_{60} \mathrm{Nb}_{40}$, as seen in Table 2 . However, ASG mounds grown on amorphous $\mathrm{Ni}_{60} \mathrm{Nb}_{40}$ were significantly larger in scale than those on polycrystalline $\mathrm{Ni}_{60} \mathrm{Nb}_{40}$. Amorphous ASG mounds were approximately $9 \mu \mathrm{m}$ taller $\left(\mathrm{R}_{\mathrm{z}}\right)$ and a $50 \%$ rougher $\left(\mathrm{R}_{\mathrm{RMS}}\right)$ than polycrystalline ASG mounds.

\subsection{Cross section analysis}

Fig. 5 shows representative cross sectional ISE images of BSG and ASG mounds on amorphous and polycrystalline $\mathrm{Ni}_{60} \mathrm{Nb}_{40}$. During the cross section preparation, Pt was deposited on top of each mound to protect the underlying microstructure from ion beam damage (labelled as "Pt"). Cross sections of BSG mounds grown on all three substrates (Fig. $5(\mathrm{a}-\mathrm{c}))$ revealed microstructures that were identical to that of the original substrates. There 
were no grain structures observed in the cross section shown in Fig. 5(a), suggesting that the amorphous $\mathrm{Ni}_{60} \mathrm{Nb}_{40}$ structure was preserved during BSG mound formation. Similarly, Fig. 5(b) and (c) shows that the microstructure of BSG mounds grown on the polycrystalline substrates were polycrystalline, unchanged from the initial substrate microstructure. EDS analysis indicated that light-colored grains were $\mathrm{Ni}_{3} \mathrm{Nb}$ and dark grey regions were $\mathrm{Ni}_{6} \mathrm{Nb}_{7}$, consistent with the results for the polycrystalline substrates discussed previously and shown in Fig. 2. Furthermore, there was no discernable change in shape, size, nor phase fraction of the $\mathrm{Ni}_{3} \mathrm{Nb}$ grains. The cross-section of the ASG mound on amorphous $\mathrm{Ni}_{60} \mathrm{Nb}_{40}$ (Fig. $5(\mathrm{~d})$ ), like that of the BSG mound, did not reveal any poly-crystalline structure. However, significant microstructural changes were observed for ASG mounds formed on both types of polycrystalline $\mathrm{Ni}_{60} \mathrm{Nb}_{40}$ substrates. Here, there was an additional layer on top of the base, original polycrystalline microstructure for both substrates. Average EDS analysis of these upper ASG mound layers showed it contained $57.0 \pm 2.0$ at. $\% \mathrm{Ni}$ and $43.0 \pm 2.0$ at. $\% \mathrm{Nb}$, close to the nominal composition of the $\mathrm{Ni}_{60} \mathrm{Nb}_{40}$ alloy. Coupled with TEM Selected Area Electron Diffraction (SAED) results (Fig. 6), it was determined that this top portion was amorphous. This same two-layered microstructure was observed in the cross sections of other ASG mounds on $100 \mathrm{~nm}$ and $2 \mu$ m polycrystalline $\mathrm{Ni}_{60} \mathrm{Nb}_{40}$ substrates. It should be noted that the vertical streaks observed in these cross-sections were due to "blanketing" that occurred during FIB milling. Such streaks are not a feature of the microstructure.

\section{Discussion}

\subsection{BSG mound formation}

The cross sectional images of their internal microstructures suggest BSG mounds form primarily through preferential valley ablation. Material removal due to ablation appeared to be the only process the substrate experienced during femtosecond laser surface processing. The thermal excursions were minimal as evident by the unchanged microstructures; the substrate material experienced temperatures below that which would induce grain growth or melting on the two types of polycrystalline $\mathrm{Ni}_{60} \mathrm{Nb}_{40}$ substrates. It is true that it may not be possible to distinguish between the original amorphous $\mathrm{Ni}_{60} \mathrm{Nb}_{40}$ microstructure and any redeposited material which was quenched fast enough to also be in the amorphous state. However, given the fact that both amorphous and polycrystalline have the same ablation threshold and the same BSG mound morphology, it can be reasoned that BSG mounds on amorphous $\mathrm{Ni}_{60} \mathrm{Nb}_{40}$ were also formed primarily by preferential valley ablation. Other studies had also reported preferential valley ablation as the dominant growth mechanism for other mound-like, below surface growth surface structures. Zuhlke et al. utilized pulse-bypulse SEM imaging of mound growth on Ni to conclude that preferential valley ablation due to scattered laser photons was primarily responsible for BSG mounds [5]. Sher et al. credited preferential valley ablation for creating spike-like surfaces on Si substrates [47]. Zhu et al. examined the differences between picosecond and femtosecond laser processing of $\mathrm{Si}$ substrate, and concluded that ablation, not fluid flow occurs during femtosecond laser surface processing due to timescales of energy relaxation processes [68]. 


\subsection{ASG mound formation}

The amorphous upper layer of an ASG mound was most likely due to fluid flow caused by the Marangoni effect, where liquid is driven from hot to cold regions of the gas-liquid interface $[69,70]$. The temperature at the bottom and sides of precursor mounds during processing was higher due to higher laser fluence, similar to preferential valley ablation as described in Fig. 1. The molten $\mathrm{Ni}_{60} \mathrm{Nb}_{40}$ that was driven up to the top of the peaks resolidifies rapidly due to the large heat sink provided by the metal substrate, resulting in amorphous phase formation. Such fluid flow has been observed on other femtosecond laser surface processed structures of this scale, such as "columns" and "spikes" on Si substrates $[48,71]$.

Vapor-liquid-solid growth mechanism could also have contributed to this top resolidification layer, as had been reported in Si substrates [48,49,55] and stainless steel [7]. It has long been known that laser processing of polycrystalline metal alloys can generate a molten layer which solidifies fast enough to result in an amorphous phase, such as reported by Sepold and Becker for $\mathrm{Fe}_{80} \mathrm{~B}_{20}$ [72].

Finally, it should be noted that ASG mounds created on amorphous $\mathrm{Ni}_{60} \mathrm{Nb}_{40}$ were significantly larger than those on poly-crystalline $\mathrm{Ni}_{60} \mathrm{Nb}_{40}$, while having the same morphology for BSG mounds. We propose this difference was due to different thermal properties of amorphous versus polycrystalline $\mathrm{Ni}_{60} \mathrm{Nb}_{40}$. It has been reported that metallic glasses have lower thermal diffusivity and conductivity than their polycrystalline counterparts [73-77]. This lower thermal conductivity would result in a thicker surface melt layer on amorphous versus polycrystalline $\mathrm{Ni}_{60} \mathrm{Nb}_{40}$, resulting in a thicker resolidification layer and taller ASG mounds.

\section{Conclusions}

We examined direct evidence of below surface growth (BSG) and above surface growth (ASG) mound formation by femtosecond laser surface processing on amorphous and polycrystalline $\mathrm{Ni}_{60} \mathrm{Nb}_{40}$ with two different average grain sizes. Utilizing dual-beam, focused ion beam scanning electron microscope, the cross-sectional microstructures of these mounds were revealed. Grain size, at least in the range examined by this study, was not a factor in BSG or ASG mound morphology. BSG mounds formed on amorphous and polycrystalline $\mathrm{Ni}_{60} \mathrm{Nb}_{40}$ have indistinguishable morphology, and are hypothesized to grow primarily by ablation, as indicated by the lack of changes in the mound microstructure relative to the base substrate material. On the other hand, an amorphous region was found to be present on the top of ASG mounds, indicating there was sufficient heating at the higher laser fluence for melting and subsequent fluid flow of the base material. Lastly, ASG mounds formed on amorphous substrates were significantly taller and with larger peak-topeak distances than those on either polycrystalline surfaces. We attribute this to lower thermal diffusivity of amorphous versus polycrystalline $\mathrm{Ni}_{60} \mathrm{Nb}_{40}$. The cross-sectional microstructural analysis supported the previously proposed formation mechanisms for femtosecond laser surface processed mound-like structures on metals: preferential valley ablation for BSG mounds and fluid flow along with preferential valley ablation for ASG mounds. 


\section{Acknowledgements}

This work was supported by National Aeronautics and Space Administration (NASA)Experimental Program to Stimulate Competitive Research (EPSCoR) Grant \#NNX13AB17A and the Office of Naval Research (ONR) Contract \#FA4600-12-d-9000-0045. Research was performed in the facilities of the Nebraska Center for Materials and Nanoscience (NCMN) and NanoEngineering Research Facility (NERF), which are supported by the Nebraska Research Initiative.

\section{References}

[1]. Sugioka K, Cheng Y, Ultrafast lasers-reliable tools for advanced materials processing, Light: Sci. Appl 3 (2014) 1-12.

[2]. Vorobyev AY, Guo C, Direct femtosecond laser surface nano/microstructuring and its applications, Laser Photonics Rev 7 (2013) 385-407.

[3]. Sugioka K, Cheng Y, Fundamentals of femtosecond laser processing, in: Laser Femtosecond 3D Micromachining for Microfluidic and Optofluidic Applications, Springer, London, 2014, pp. 1933.

[4]. Vorobyev AY, Guo C, Femtosecond laser modification of material wetting properties: a brief review, Sci. Adv. Mater 4 (2012) 432-438.

[5]. Zuhlke CA, Anderson TP, Alexander DR, Formation of multiscale surface structures on nickel via above surface growth and below surface growth mechanisms using femtosecond laser pulses, Opt. Express 21 (2013) 8460-8473. [PubMed: 23571936]

[6]. Tsukamoto M, Kayahara T, Nakano H, Hashida M, Katto M, Fujita M, Tanaka M, Abe N, Microstructures formation on titanium plate by femtosecond laser ablation, J. Phys.: Conf. Ser 59 (2007) 666-669.

[7]. Ling EJY, Saïd J, Brodusch N, Gauvin R, Servio P, Kietzig A-M, Investigating and understanding the effects of multiple femtosecond laser scans on the surface topography of stainless steel 304 and titanium, Appl. Surf. Sci 353 (2015) 512-521.

[8]. Nayak BK, Gupta MC, Self-organized micro/nano structures in metal surfaces by ultrafast laser irradiation, Opt. Lasers Eng 48 (2010) 940-949.

[9]. Pan A, Dias A, Gomez-Aranzadi M, Olaizola SM, Rodriguez A, Formation of laser-induced periodic surface structures on niobium by femtosecond laser irradiation, J. Appl. Phys 115 (2014) 173101.

[10]. Barada KN, Mool CG, Kurt WK, Spontaneous formation of nanospiked microstructures in germanium by femtosecond laser irradiation, Nanotechnology 18 (2007) 195302.

[11]. Tull BR, Carey JE, Mazur E, McDonald JP, Yalisove SM, Silicon surface morphologies after femtosecond laser irradiation, MRS Bull 31 (2006) 626-633.

[12]. Rebollar E, Castillejo M, Ezquerra TA, Laser induced periodic surface structures on polymer films: from fundamentals to applications, Eur. Polym. J 73 (2015) 162-174.

[13]. Rebollar E, Vazquez de Aldana JR, Martin-Fabiani I, Hernandez M, Rueda DR, Ezquerra TA, Domingo C, Moreno P, Castillejo M, Assessment of femtosecond laser induced periodic surface structures on polymer films, PCCP 15 (2013) 11287-11298. [PubMed: 23728307]

[14]. Pazokian H, Selimis A, Jalal B, Saeid J, Mahmoud M, Fotakis C, Stratakis E, Tailoring the wetting properties of polymers from highly hydrophilic to superhydrophobic using UV laser pulses, J. Micromech. Microeng 22 (2012) 035001.

[15]. Boinovich LB, Domantovskiy AG, Emelyanenko AM, Pashinin AS, Ionin AA, Kudryashov SI, Saltuganov PN, Femtosecond laser treatment for the design of electro-insulating superhydrophobic coatings with enhanced wear resistance on glass, ACS Appl. Mater. Interfaces 6 (2014) 2080-2085. [PubMed: 24456120]

[16]. Ahsan MS, Dewanda F, Lee MS, Sekita H, Sumiyoshi T, Formation of superhydrophobic sodalime glass surface using femtosecond laser pulses, Appl. Surf. Sci 265 (2013) 784-789.

[17]. Sciti D, Silvestroni L, Trucchi DM, Cappelli E, Orlando S, Sani E, Femtosecond laser treatments to tailor the optical properties of hafnium carbide for solar applications, Sol. Energy Mater. Sol. Cells 132 (2015) 460-466. 
[18]. Xing Y, Deng J, Lian Y, Zhang K, Zhang G, Zhao J, Multiple nanoscale parallel grooves formed on Si3N4/TiC ceramic by femtosecond pulsed laser, Appl. Surf. Sci 289 (2014) 62-71.

[19]. Warrender JM, Laser hyperdoping silicon for enhanced infrared optoelectronic properties, Appl. Phys. Rev 3 (2016) 031104.

[20]. Franta B, Pastor D, Aziz M, Mazur E, Optical annealing of black silicon, in: Di Bartolo B, Collins J, Silvestri L (Eds.), Nano-Structures for Optics and Photonics: Optical Strategies for Enhancing Sensing, Imaging, Communication and Energy Conversion, Springer, Netherlands, Dordrecht, 2015, 491-491.

[21]. Wang H, Kongsuwan P, Satoh G, Yao YL, Femtosecond laser-induced simultaneous surface texturing and crystallization of a-Si: H thin film: absorption and crystallinity, J. Manuf. Sci. Eng 134 (2012) 1-10.

[22]. Iyengar VV, Nayak BK, Gupta MC, Optical properties of silicon light trapping structures for photovoltaics, Sol. Energy Mater. Sol. Cells 94 (2010) 2251-2257.

[23]. Lancry M, Desmarchelier R, Cook K, Canning J, Poumellec B, Record retardance in silica and compact waveplates and related optical components photo-induced by femtosecond laser, in: Adv. Photonics, Optical Society of America, Barcelona, 2014.

[24]. Zhou S, Pi X, Ni Z, Luan Q, Jiang Y, Jin C, Nozaki T, Yang D, Boron- and phosphorushyperdoped silicon nanocrystals, Part. Part. Syst. Charact 32 (2014) 213-221.

[25]. Rukosuyev MV, Lee J, Cho SJ, Lim G, Jun MBG, One-step fabrication of superhydrophobic hierarchical structures by femtosecond laser ablation, Appl. Surf. Sci 313 (2014) 411-417.

[26]. Kietzig A-M, Hatzikiriakos SG, Englezos P, Patterned superhydrophobic metallic surfaces, Langmuir 25 (2009) 4821-4827. [PubMed: 19267439]

[27]. Yong J, Chen F, Yang Q, Farooq U, Hou X, Photoinduced switchable underwater superoleophobicity-superoleophilicity on laser modified titanium surfaces, J. Mater. Chem A 3 (2015) 10703-10709.

[28]. Kruse CM, Anderson T, Wilson C, Zuhlke C, Alexander D, Gogos G, Ndao S, Enhanced poolboiling heat transfer and critical heat flux on femtosecond laser processed stainless steel surfaces, Int. J. Heat Mass Transf 82 (2015) 109-116.

[29]. Vorobyev AY, Guo C, Superwicking surfaces produced by femtosecond laser, in: Shulika O, Sukhoivanov I (Eds.), Advanced Lasers, Springer, Netherlands, 2015, pp. 101-115.

[30]. Kruse C, Anderson T, Wilson C, Zuhlke C, Alexander D, Gogos G, Ndao S, Extraordinary shifts of the leidenfrost temperature from multiscale micro/nanostructured surfaces, Langmuir 29 (2013) 9798-9806. [PubMed: 23799305]

[31]. Zorba V, Stratakis E, Barberoglou M, Spanakis E, Tzanetakis P, Anastasiadis SH, Fotakis C, Biomimetic artificial surfaces quantitatively reproduce the water repellency of a lotus leaf, Adv. Mater 20 (2008) 4049-4054.

[32]. Fadeeva E, Truong VK, Stiesch M, Chichkov BN, Crawford RJ, Wang J, Ivanova EP, Bacterial retention on superhydrophobic titanium surfaces fabricated by femtosecond laser ablation, Langmuir 27 (2011) 3012-3019. [PubMed: 21288031]

[33]. Dumas V, Rattner A, Vico L, Audouard E, Dumas JC, Naisson P, Bertrand P, Multiscale grooved titanium processed with femtosecond laser influences mesenchymal stem cell morphology, adhesion, and matrix organization, J. Biomed. Mater. Res Part A 100A (2012) 3108-3116.

[34]. Ahmmed KMT, Kietzig A-M, Drag reduction on laser-patterned hierarchical superhydrophobic surfaces, Soft Mat (2016).

[35]. Li G, Lu Y, Wu P, Zhang Z, Li J, Zhu W, Hu Y, Wu D, Chu J, Fish scale inspired design of underwater superoleophobic microcone arrays by sucrose solution assisted femtosecond laser irradiation for multifunctional liquid manipulation, J. Mater. Chem A 3 (2015) 18675-18683.

[36]. Zuhlke CA, Anderson TP, Alexander DR, Fundamentals of layered nanoparticle covered pyramidal structures formed on nickel during femtosecond laser surface interactions, Appl. Surf. Sci 283 (2013) 648-653.

[37]. Nayak BK, Gupta MC, Kolasinski KW, Formation of nano-textured conical microstructures in titanium metal surface by femtosecond laser irradiation, Appl. Phys A 90 (2008) 399-402. 
[38]. Li Y, Cui Z, Wang W, Lin C, Tsai H-L, Formation of linked nanostructure-textured moundshaped microstructures on stainless steel surface via femtosecond laser ablation, Appl. Surf. Sci 324 (2015) 775-783.

[39]. Bonse J, Koter R, Hartelt M, Spaltmann D, Pentzien S, Höhm S, Rosenfeld A,Krüger J, Femtosecond laser-induced periodic surface structures on steel and titanium alloy for tribological applications, Appl. Phys A 117 (2014) 103-110.

[40]. Zuhlke CA, Anderson TP, Alexander DR, Comparison of the structural and chemical composition of two unique micro/nanostructures produced by femtosecond laser interactions on nickel, Appl. Phys. Lett 103 (2013) 121603.

[41]. Kuršelis K, Kiyan R, Chichkov BN, Formation of corrugated and porous steel surfaces by femtosecond laser irradiation, Appl. Surf. Sci 258 (2012) 8845-8852.

[42]. Moradi S, Kamal S, Englezos P, Hatzikiriakos SG, Femtosecond laser irradiation of metallic surfaces: effects of laser parameters on superhydrophobicity, Nanotechnology 24 (2013) 415302. [PubMed: 24045766]

[43]. Zuhlke CA, Control and understanding of the formation of micro/nanostructured metal surfaces using femtosecond laser pulses, in: Electrical Engineering, University of Nebraska-Lincoln, Lincoln, Nebraska, 2012.

[44]. Shirk MD, Molian PA, A review of ultrashort pulsed laser ablation of materials, J. Laser Appl 10 (1998) 18-28.

[45]. Atanasov PA, Nedialkov NN, Imamova SE, Ruf A, Hügel H, Dausinger F, Berger P, Laser ablation of Ni by ultrashort pulses: molecular dynamics simulation, Appl. Surf. Sci 186 (2002) 369-373.

[46]. Peng E, Tsubaki A, Zuhlke CA, Wang M, Bell R, Lucis MJ, Anderson TP, Alexander DR, Gogos $\mathrm{G}$, Shield JE, Experimental explanation of the formation mechanism of surface mound-structures by femtosecond laser on polycrystalline Ni60Nb40, Appl. Phys. Lett 108 (2016) 031602.

[47]. Sher M-J, Winkler MT, Mazur E, Pulsed-laser hyperdoping and surface texturing for photovoltaics, MRS Bull 36 (2011) 439-445.

[48]. Sánchez F, Morenza JL, Aguiar R, Delgado JC, Varela M, Dynamics of the hydrodynamical growth of columns on silicon exposed to ArF excimer-laser irradiation, Appl. Phys A 66 (1998) $83-86$.

[49]. Tsibidis GD, Fotakis C, Stratakis E, From ripples to spikes: a hydrodynamical mechanism to interpret femtosecond laser-induced self-assembled structures, Phys. Rev B 92 (2015) 041405.

[50]. Yong Hwang T, Guo C, Polarization and angular effects of femtosecond laser-induced conical microstructures on Ni, J. Appl. Phys 111 (2012) 083518.

[51]. Wu Z, Zhu X, Zhang N, Time-resolved shadowgraphic study of femtosecond laser ablation of aluminum under different ambient air pressures, J. Appl. Phys 109 (2011) 053113.

[52]. Choi TY, Grigoropoulos CP, Plasma and ablation dynamics in ultrafast laser processing of crystalline silicon, J. Appl. Phys 92 (2002) 4918-4925.

[53]. Varlamova O, Martens C, Ratzke M, Reif J, Genesis of femtosecond-induced nanostructures on solid surfaces, Appl. Opt 53 (2014) I10-I15. [PubMed: 25402932]

[54]. Tan B, Venkatakrishnan K, A femtosecond laser-induced periodical surface structure on crystalline silicon, J. Micromech. Microeng 16 (2006) 1080.

[55]. Tsibidis GD, Barberoglou M, Loukakos PA, Stratakis E, Fotakis C, Dynamics of ripple formation on silicon surfaces by ultrashort laser pulses in subablation conditions, Phys. Rev B 86 (2012) 115316.

[56]. Römer GRBE, Huis in't Veld AJ, Meijer J, Groenendijk MNW, On the formation of laser induced self-organizing nanostructures, CIRP Ann. - Manufactur. Technol 58 (2009) 201-204.

[57]. Koch CC, Cavin OB, McKamey CG, Scarbrough JO, Preparation of "amorphous" Ni60Nb40 by mechanical alloying, Appl. Phys. Lett 43 (1983) 1017-1019.

[58]. Barbee TW, Holmes WH, Keith DL, Pyzyna MK, Ilonca G, Synthesis of amorphous niobiumnickel alloys by vapor quenching, Thin Solid Films 45 (1977) 591-599.

[59]. Liu JM, Simple technique for measurements of pulsed Gaussian-beam spot sizes, Opt. Lett 7 (1982) 196-198. [PubMed: 19710869] 
[60]. Snow D, Laser surface melting of metals and alloys, in: Davis R, Palmour H, III, Porter R (Eds.), Emergent Process Methods for High-Technology Ceramics, Springer, US, 1984, pp. 461-471.

[61]. Jia J, Li M, Thompson CV, Amorphization of silicon by femtosecond laser pulses, Appl. Phys. Lett 84 (2004) 3205-3207.

[62]. Williams DB, Carter CB, Transmission Electron Microscopy: A Textbook for Materials Science, Springer, 2009.

[63]. Giannuzzi LA, Stevie FA, A review of focused ion beam milling techniques for TEM specimen preparation, Micron 30 (1999) 197-204.

[64]. Kejun Z, Xianzhang Z, Zhanpeng J, A thermodynamic calculation of the Ni-Nb phase diagram, J. Alloys Compd 179 (1992) 177-185.

[65]. Kejun Z, Zhanpeng J, Thermodynamic modeling of intermetallic compounds in the Ni-Nb system, Scr. Metall. Mater 26 (1992) 417-422.

[66]. Okamoto H, Nb-Ni (niobium-nickel), J. Ph. Equilib 19 (1998), 289-289.

[67]. Wang H, Kongsuwan P, Satoh G, Yao YL, Femtosecond laser-induced simultaneous surface texturing and crystallization of a-Si:H thin film: morphology study, Int. J. Adv. Manuf. Technol 65 (2013) 1691-1703.

[68]. Zhu J, Yin G, Zhao M, Chen D, Zhao L, Evolution of silicon surface microstructures by picosecond and femtosecond laser irradiations, Appl. Surf. Sci 245 (2005) 102-108.

[69]. Lu Y, Theppakuttai S, Chen SC, Marangoni effect in nanosphere-enhanced laser nanopatterning of silicon, Appl. Phys. Lett 82 (2003) 4143-4145.

[70]. Korte F, Koch J, Chichkov BN, Formation of microbumps and nanojets on gold targets by femtosecond laser pulses, Appl. Phys A 79 (2004) 879-881.

[71]. Sánchez F, Morenza JL, Trtik V, Characterization of the progressive growth of columns by excimer laser irradiation of silicon, Appl. Phys. Lett 75 (1999) 3303-3305.

[72]. Sepold G, Becker R, Rapid solidification by laser beam techniques, in: Science and Technology of the Undercooled Melt, Springer, 1986, pp. 112-120.

[73]. Yamasaki M, Kagao S, Kawamura Y, Thermal diffusivity and conductivity of Zr55A110Ni5Cu30 bulk metallic glass, Scripta Mater. 53 (2005) 63-67.

[74]. Yamasaki M, Kagao S, Kawamura Y, Yoshimura K, Thermal diffusivity and conductivity of supercooled liquid in Zr41Ti14Cu12Ni10Be23 metallic glass, Appl. Phys. Lett 84 (2004) 46534655.

[75]. Axinte E, Metallic glasses from alchemy to pure science: present and future of design, processing and applications of glassy metals, Mater. Des 35 (2012) 518-556.

[76]. Choy CL, Tong KW, Wong HK, Leung WP, Thermal conductivity of amorphous alloys above room temperature, J. Appl. Phys 70 (1991) 4919-4925.

[77]. Zhou Z, Uher C, Xu D, Johnson WL, Gannon W, Aronson MC, On the existence of Einstein oscillators and thermal conductivity in bulk metallic glass, Appl. Phys. Lett 89 (2006) 031924.

Appl Surf Sci. Author manuscript; available in PMC 2018 November 06. 
(a)

(b)

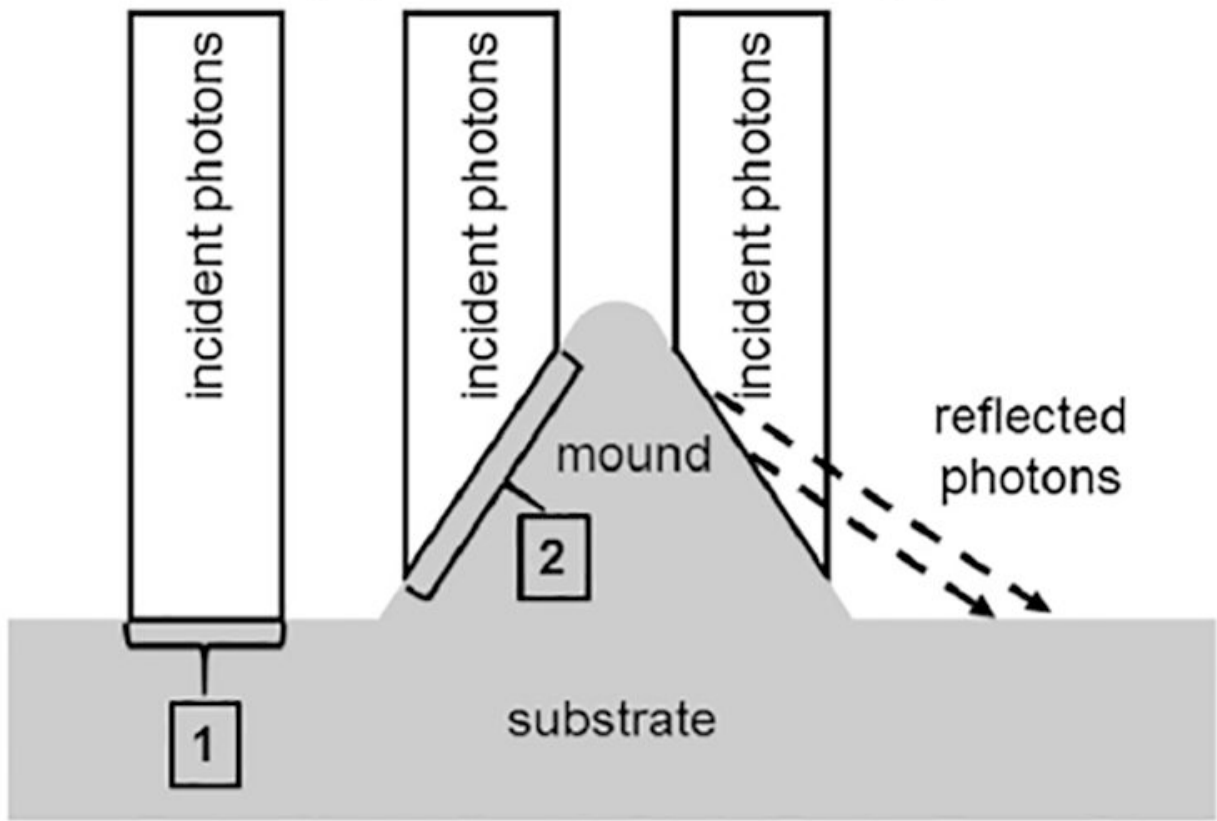

Fig. 1.

Diagram of the preferential valley ablation mechanism of (a) differences in subtended area and (b) scattered photons. 


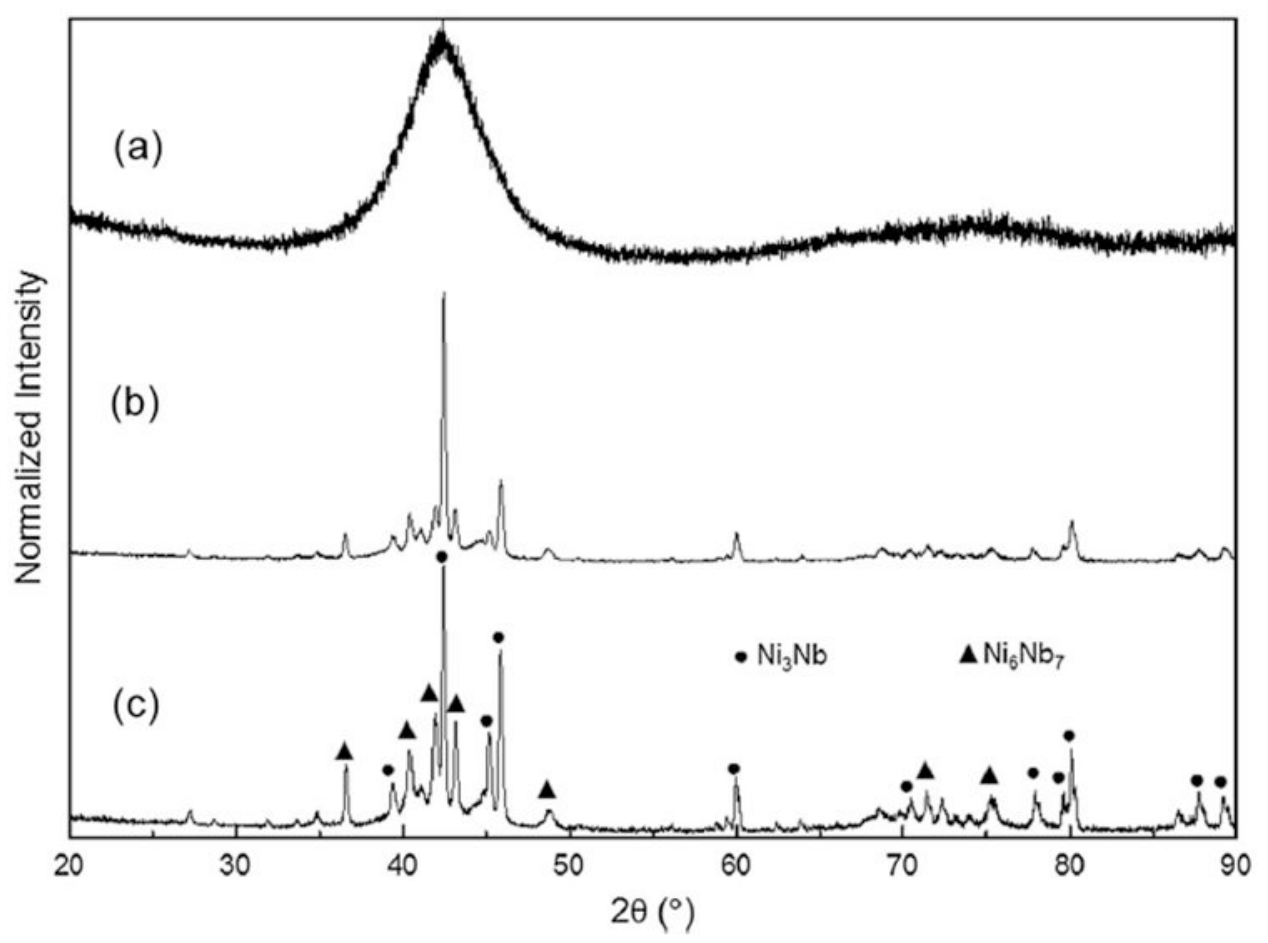

Fig. 2.

X-ray diffraction patterns of (a) as-solidified $\mathrm{Ni}_{60} \mathrm{Nb}_{40}$ ribbons displaying an amorphous structure, and after heat treatment at $1373 \mathrm{~K}$ for (b) $2 \mathrm{~h}$ and (c) $20 \mathrm{~h}$. Diffraction peaks were indexed to $\mathrm{Ni}_{3} \mathrm{Nb}$ and $\mathrm{Ni}_{6} \mathrm{Nb}_{7}$. 

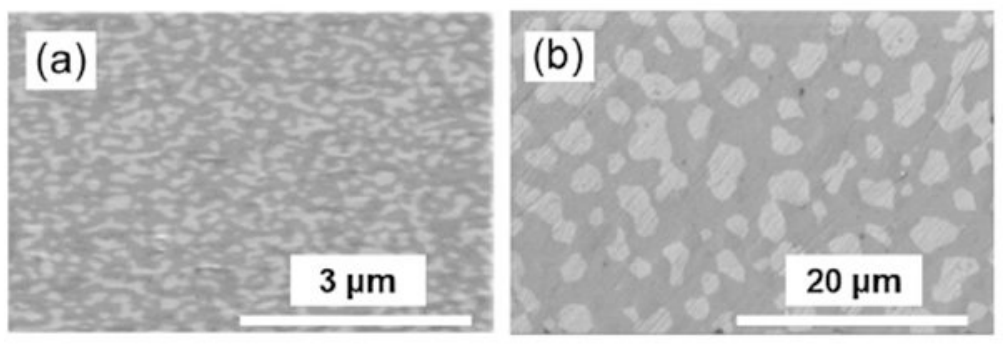

Fig. 3.

SEM images of polycrystalline $\mathrm{Ni}_{60} \mathrm{Nb}_{40}$ displaying $\mathrm{Ni}_{6} \mathrm{Nb}_{7}$ (dark grey) and $\mathrm{Ni}_{3} \mathrm{Nb}$ (light grey) phases after annealing at $1373 \mathrm{~K}$ for (a) $2 \mathrm{~h}$ and (b) $20 \mathrm{~h}$, with average grain sizes of $100 \mathrm{~nm}$ and $2 \mu \mathrm{m}$, respectively. 

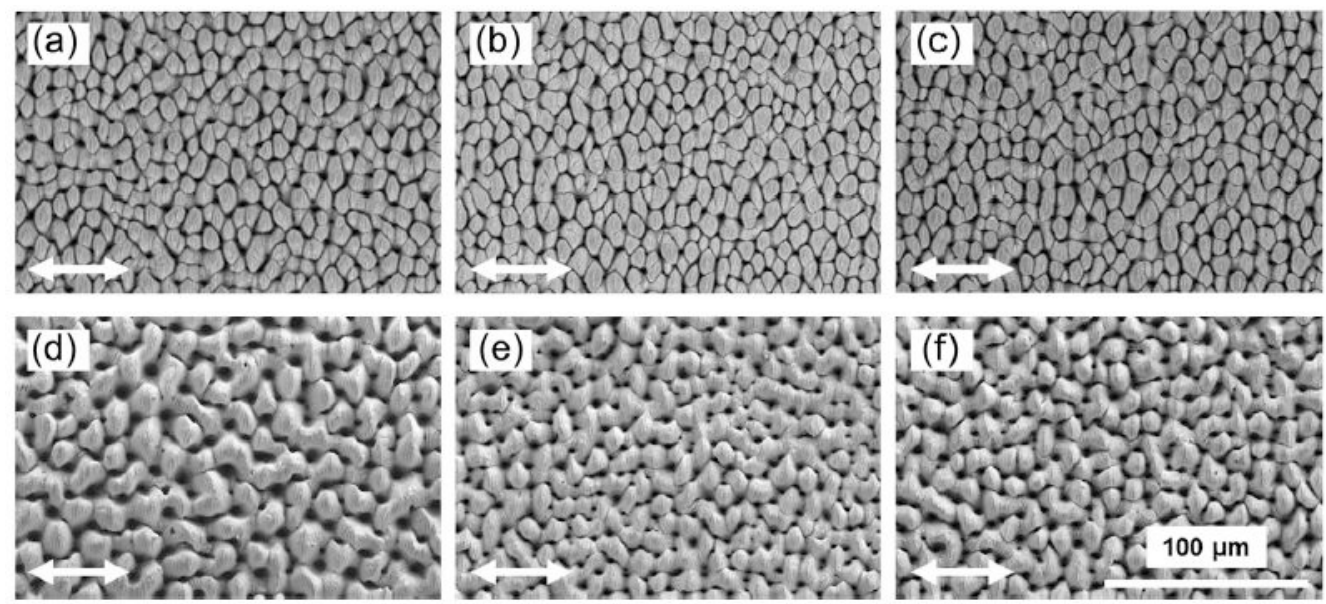

Fig. 4.

SEM images of BSG mounds on (a) amorphous $\mathrm{Ni}_{60} \mathrm{Nb}_{40}$ substrate, (b) polycrystalline $\mathrm{Ni}_{60} \mathrm{Nb}_{40}$ substrate with $100 \mathrm{~nm}$ average grain size, and (c) with $2 \mu \mathrm{m}$ average grain size. SEM images of ASG mounds on (d) amorphous $\mathrm{Ni}_{60} \mathrm{Nb}_{40}$ substrate, (e) polycrystalline $\mathrm{Ni}_{60} \mathrm{Nb}_{40}$ substrate with $100 \mathrm{~nm}$ average grain size, and (f) with $2 \mu \mathrm{m}$ average grain size. The double-ended arrow indicate laser polarization direction. 

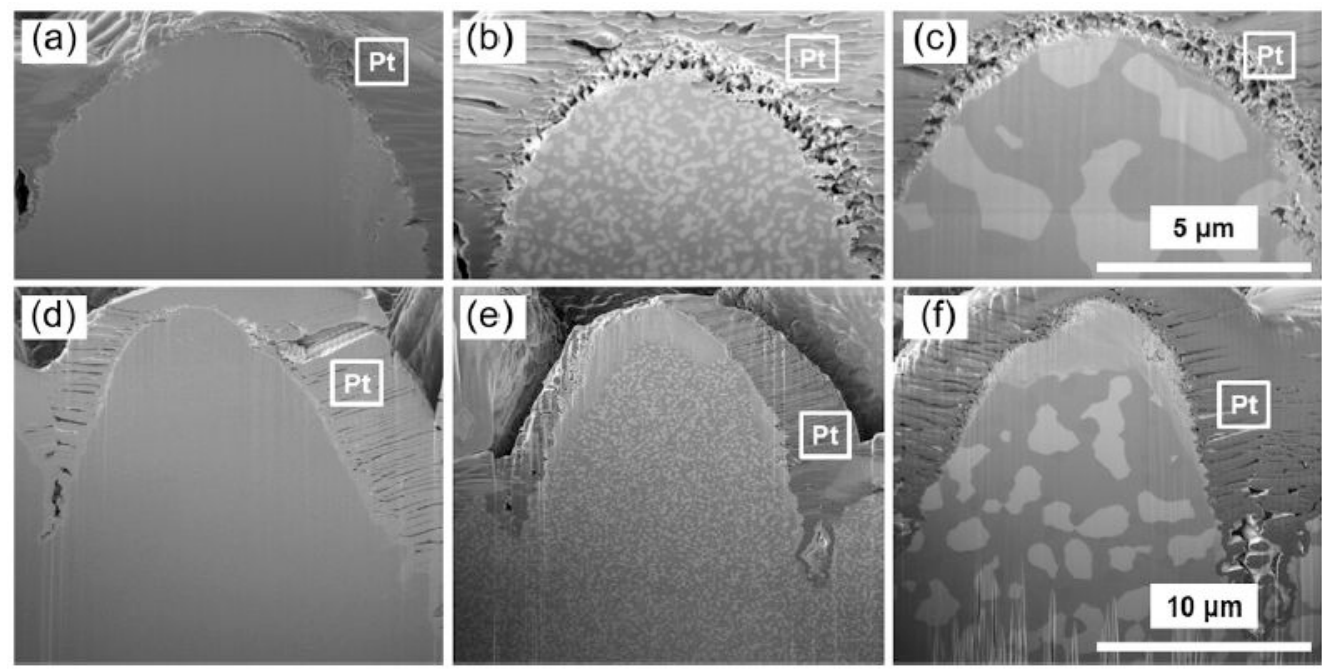

Fig. 5.

ISE cross section images of BSG mounds on (a) amorphous $\mathrm{Ni}_{60} \mathrm{Nb}_{40}$ substrate, (b) polycrystalline $\mathrm{Ni}_{60} \mathrm{Nb}_{40}$ substrate with $100 \mathrm{~nm}$ average grain size, and (c) with $2 \mu \mathrm{m}$ average grain size. ISE cross section images of ASG mounds on (d) amorphous $\mathrm{Ni}_{60} \mathrm{Nb}_{40}$ substrate, (e) polycrystalline $\mathrm{Ni}_{60} \mathrm{Nb}_{40}$ substrate with $100 \mathrm{~nm}$ average grain size, and (f) with 2 [H9262]m average grain size. "Pt" indicates the deposited protective Pt layers. 

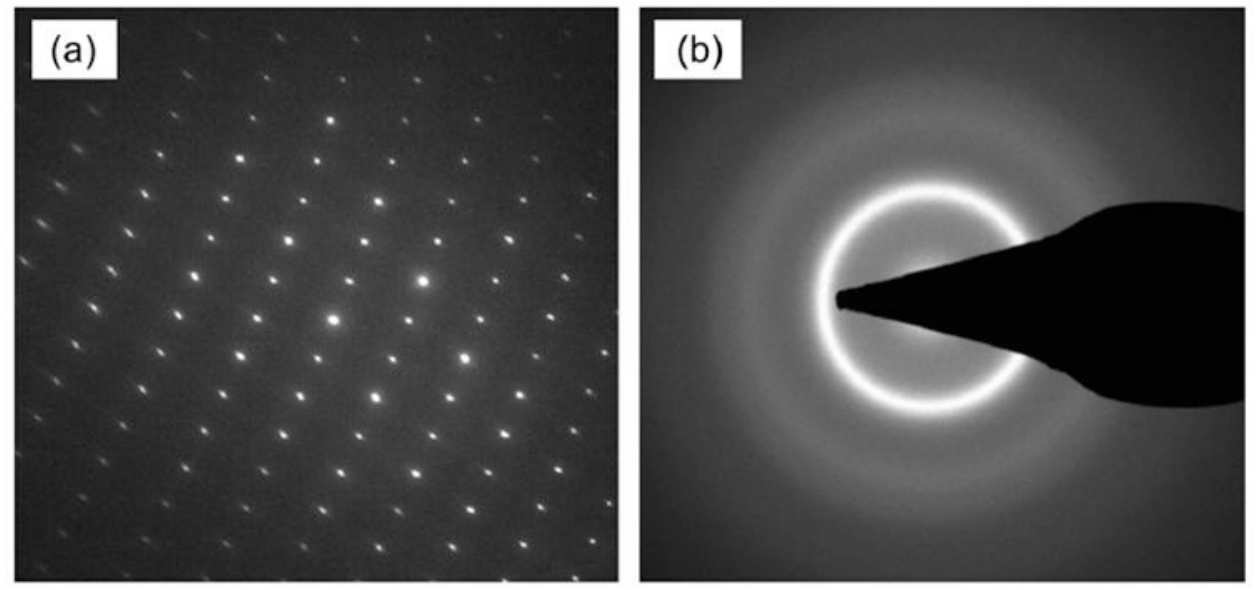

Fig. 6.

TEM SAED pattern of the (a) original $2 \mu \mathrm{m}$ grain size polycrystalline $\mathrm{Ni60Nb40} \mathrm{(b)}$ amorphous $\mathrm{Ni}_{60} \mathrm{Nb}_{40}$ top portion of the ASG mound. 


\section{Table 1}

Spot radius and threshold fluence of amorphous and polycrystalline $\mathrm{Ni}_{60} \mathrm{Nb}_{40}$ with $100 \mathrm{~nm}$ and $2 \mu \mathrm{m}$ average grain sizes.

\begin{tabular}{llll}
\hline & Amorphous & $\begin{array}{l}\text { Polycrystalline } \\
(\mathbf{1 0 0 n m})\end{array}$ & $\begin{array}{l}\text { Polycrystalline } \\
(\mathbf{2} \boldsymbol{\mu m})\end{array}$ \\
\hline Spot radius $(\mu \mathrm{m})$ & $103.5 \pm 1.7$ & $103.8 \pm 1.4$ & $102.4 \pm 2.7$ \\
Threshold fluence $\left(\mathrm{J} \mathrm{cm}^{-2}\right)$ & $0.100 \pm 0.004$ & $0.104 \pm 0.002$ & $0.102 \pm 0.07$ \\
\hline
\end{tabular}




\section{Table 2}

Average peak-to-peak distance (PPD), surface area-to-geometric area ratio (SA/GA), and roughness $\left(\mathrm{R}_{\mathrm{z}}\right.$, $\mathrm{R}_{\mathrm{RMS}}$ ) for BSG mounds on amorphous and polycrystalline $\mathrm{Ni}_{60} \mathrm{Nb}_{40}$ with $100 \mathrm{~nm}$ and $2 \mu \mathrm{m}$ average grain size (D).

\begin{tabular}{|c|c|c|c|}
\hline $\begin{array}{l}\text { Morphology } \\
\text { Parameter }\end{array}$ & Amorphous & Polycrystalline $(D=100$ nm) & $\begin{array}{l}\text { Polycrystalline } \\
(\mathrm{D}=2 \mu \mathrm{m})\end{array}$ \\
\hline $\operatorname{PPD}(\mu \mathrm{m})$ & $7.7 \pm 0.2$ & $8.0 \pm 0.2$ & $7.9 \pm 0.10$ \\
\hline SA/GA & $4.02 \pm 0.11$ & $3.94 \pm 0.09$ & $3.88 \pm 0.11$ \\
\hline $\mathrm{R}_{\mathrm{Z}}(\mu \mathrm{m})$ & $15.6 \pm 1.1$ & $14.5 \pm 0.9$ & $14.6 \pm 1.1$ \\
\hline $\mathrm{R}_{\mathrm{RMS}}(\mu \mathrm{m})$ & $3.0 \pm 0.2$ & $2.8 \pm 0.2$ & $2.8 \pm 0.2$ \\
\hline
\end{tabular}




\section{Table 3}

Average peak-to-peak distance (PPD), surface area-to-geometric area ratio (SA/GA), and roughness $\left(\mathrm{R}_{\mathrm{z}}\right.$, $\mathrm{R}_{\mathrm{RMS}}$ ) for ASG mounds on amorphous and polycrystalline $\mathrm{Ni}_{60} \mathrm{Nb}_{40}$ with $100 \mathrm{~nm}$ and $2 \mu$ m average grain size (D).

\begin{tabular}{llll}
\hline $\begin{array}{l}\text { Morphology } \\
\text { Parameter }\end{array}$ & Amorphous & Polycrystalline (D= 100 nm) & $\begin{array}{l}\text { Polycrystalline } \\
(\mathbf{D = 2} \mathbf{\mu m})\end{array}$ \\
\hline $\mathrm{PPD}(\mu \mathrm{m})$ & $15.1 \pm 1.6$ & $12.1 \pm 1.8$ & $13.3 \pm 1.6$ \\
$\mathrm{SA} / \mathrm{GA}$ & $5.6 \pm 0.3$ & $4.3 \pm 0.3$ & $4.5 \pm 0.2$ \\
$\mathrm{R}_{\mathrm{Z}}(\mu \mathrm{m})$ & $28.8 \pm 2.4$ & $19.4 \pm 2.3$ & $20.2 \pm 2.0$ \\
$\mathrm{R}_{\mathrm{RMS}}(\mu \mathrm{m})$ & $6.0 \pm 0.7$ & $3.9 \pm 0.5$ & $4.1 \pm 0.5$ \\
\hline
\end{tabular}

